\title{
Learning Analytics Tool Adoption by University Students
}

\author{
Seren Başaran ${ }^{1}$ (i) \\ Near East University, Department of Computer Information \\ Systems, Lefkoşa 98010 via: Mersin 10 Turkey, Cyprus
}

\author{
Ahmed Mohamed Daganni ${ }^{2}$ \\ College of Energy Technologies, Renewable Energy \\ Department, Jakherra, Libya
}

\begin{abstract}
Learning analytics refers to a systematic process involving measuring, collecting, analyzing and reporting data about learners with the aim of fully understanding how best learning environments can be optimized to increase efficiency. The aim of this study is to understand the factors contributing to the learning analytics adoption by university students in North Cyprus. Participants comprised of students from three universities in North Cyprus. 718 valid questionnaires involving items from the adopted UTAUT (Unified Theory of Acceptance and Use of Technology) model was used in the study. The results have shown that there was a weak negative correlation between Performance Expectancy and Technology Use Intention implying that when students are aware of how a technology operates and if it satisfies their requirements, then they will be ready to adopt learning analytics. There was also a negative weak correlation between Effort Expectancy and Technology Use Intention. A positive weak correlation between Social Influence and Technology Use Intention was observed while there was a negative weak correlation between Technology Use Intention and Technology Use Behavior implying that when a students have intentions of using learning analytics, they show a positive behavior towards the technology. The study also shows that there was also moderate positive correlation between Technology Anxiety and Technology User Behavior. This study is considered to be of great benefit and practical implementation to researchers, instructors, students, universities and the ministry of education.
\end{abstract}

Keywords-Higher education; learning analytics; learning tools; North Cyprus; students; technology

\section{INTRODUCTION}

Learning analytics refers to a systematic process involving measuring, collecting, analyzing and reporting data about learners with the aim of fully understanding how learning environments can be optimized to increase efficiency and effectiveness. Various learning analytical tools have been discovered through research and developed in a bid to improve the overall learning experience. Educators play an important role in determining which analytical tool best suits learners considering how the tool supports both pedagogical as well as organizational goals [1]. A digital footprint is left behind each time a student uses a university services as student information system, learning management system, library login, logging in to the virtual learning systems or submitting online assignments. Learning analytics is the process of thoroughly analyzing the digital footprint to get more information about the users of the system which can help enhance the overall learning process [2].
Due to the recent "smart" advancements in the technology sector and considering recent globally emerging covid-19 breakout there is an urgent need to shift from traditional paper and pencil approach to a digitally extracting meaning from students' progress, learning activities etc... and hence moving away from the traditional paper-based usage in an attempt to keep up with the standards of education in North Cyprus due to the increasing number of students for every academic semester. Adopting learning analytics in the educational sector has led to higher retention levels and prediction of drop-outs allowing institutions and instructors to be proactive hence improving the entire learning process in some countries such as Australia, UK, America and Italy [3]. Learning analytics have been used by instructors in improving their overall teaching experience as well as by institutions in fostering good learning practices and improving the entire learning system. In addition, learning analytics can be used to effectively monitor engagements among students and boost participation and to improve attainment levels by offering support to struggling students. For such reasons, understanding the acceptance and adoption of learning analytics play a vital role.

Learning analytics also play a crucial role in improving the overall educational sector and enhancing the learning environment. Below are reasons why learning analytics are important to various educational stakeholders: Learning analytics enable students to monitor their performance based on their set goals and check how others are performing which can endorse motivation. Learning analytics gives more insight to the student on the areas they need to improve in order for them to obtain better grades. The instructors or teachers will be able to monitor their students' progress in real time and get more insight on their performance. Students lagging behind can be easily identified and the instructor will be able to be proactive and assist the students before they fail hence improving retention levels. Training managers will be able to identify educational stakeholders as students or teachers who are lagging behind or are having difficulties in using the system and training managers will be able to focus on problematic groups only. By making use of learning analytics, institutions will be able to retain more students through once proactive measures taken once signals are seen on students underperforming and dropout levels are also minimized. Researchers who are interested in knowing how best learning analytics can be adopted in educational settings will be interested in this study. 


\section{LITERATURE REVIEW}

With the emergence of new technologies and global covid19 pandemic, the world is now undergoing what is known as data revolution where massive data is being generated from various sources in great speed according to [4] it is projected that the quantity of such data will double its current rate each month. The emergence and adoption of new technology in the educational sector has resulted in a massive influx of data however the emerging issue is that this data has been used inefficiently to improve the entire educational sector [5].

In a recent study conducted by [6], students indicated that although the use of learning analytics has had a significant impact in their personal studies they are not keen on sharing their digital footprints with the university and instructors as they feel it is invasion of privacy. Students feel uncomfortable in the learning environment knowing that all their browsing history will be analyzed by their instructors. However, on the contrary, instructors feel that by gaining access to such valuable data that is the only way they will be able to identify the needs of students and see how best they can help each student at an individual level.

It has also been noted that tools available on the student dashboard to show student progress relative to their own learning goals are motivating although in a number of cases it has also been reported that successful students are the ones who tend to use these tools more compared to struggling students [5]. This shows the need for educating all students on the effective use of such tools so that a vibrant picture and clear results can be derived based on all students despite their intellectual level and ability. It was also noted that an increase in student performance as a result of using learning analytics had a positive impact on other courses as well which the same student is studying. It is also vital to note where [7] reported that objections by students on the use of learning analytics has not been reported in the literature by many researchers.

As technology keeps on advancing each day in different sectors, the educational sector is also not being left behind. Many researchers in the literature have explained the importance of this technology and how it is revolutionizing the educational sector. Some of the advantages for adopting learning analytics in the educational sector can be summarized as:

- As a tool for quality assurance and quality improvement: Learning analytics have been used by instructors in improving their overall teaching experience as well as by institutions in fostering best learning practices and improving the entire learning system. Learning analytics data could be used as a submission for institutions as evidence of support for Teaching Excellence Framework (TEF) applications. At the University of Maryland, it was found out that use of learning analytics resulted in quality teaching and improved student and instructor relationships [2].

- As a tool for boosting retention levels: Using learning analytics helps instructors and the institution to identify students that are at risk and proactive intervention can be done quickly hence retention levels are boosted. At
Purdue University, problems related to retention and the identification of students at risk can now be done within the second week and measures are quickly taken which is something that could not be done before [2]. Student data analytics can be used to predict the students who will not make it to the next semester at New York Institute of Technology (NYIT). 75\% of the students who do not progress to the next semester would have been predicted at risk by the learning analytics model.

- As a tool used for analyzing differential outcomes among students: Learning analytics can be used to effectively monitor engagements among students and boost participation and to improve attainment levels by offering support to struggling students [6].

- For the development of adaptive learning: This refers to personalized learning that is delivered at an individual basis based on one's capability to retain information and is also based on one's schedule [2].

According to authors in [2], adopting learning analytics in higher education has the power to provide students make well informed decisions on their own by monitoring their overall performance in real time and have control over their progress and what they wish to study based on results projected. A study conducted at Nottingham Trent University in the UK showed that $89 \%$ of the students considered signals as positive experiences whilst on the other hand $74 \%$ stated that their motivation level was increased by using analytic tools. In addition students reported that by being able to see their own engagement online, it had a positive spur for them to stay engaged.

Researchers in [3] conducted a study at many universities across USA to fully understand the adoption of learning analytics. In the second week of the term, instructors identified problems as far as learning analytics deployment was concerned. Students were in need of help more frequently, however this led to $12 \%$ more $\mathrm{B}$ grades and $\mathrm{C}$ grades and failure rates for grade $\mathrm{D}$ and $\mathrm{F}$ dropped by $14 \%$.

At Maryland University in the United States, learning analytics through the use of virtual learning environments (VLE) has made it possible for instructors to identify effective teaching strategies that could be deployed on other courses and the analysis which was found made it clear that students who obtain low grades use the system $40 \%$ less than those who get $\mathrm{C}$ grades or even higher grades [3]. In addition, the researchers conducted a study at California State University found out that students were motivated by the use of the virtual learning system and this increased their passing grades by $25 \%$.

A study conducted at Marist College in New York showed that predictive models were a key to students in giving them early feedback and therefore allowed them to be proactive and this resulted in a $6 \%$ increase in student's final grades. Furthermore, study conducted at New York Institute of Technology showed that $74 \%$ of dropouts were already predicted by the system and this information is vital to 
instructors as they can support students who are at risk of dropping out and dropout rates can fall [3].

A study conducted at Nottingham Trent University in the UK showed that there was a strong link with retention levels, a quarter of the students who had low average engagement were able to progress to the second year. In addition there was a strong link with achievement levels as well with $81 \%$ of the students graduating with a first class and the ratio was 2:1 degree contrary to the $42 \%$ who had low engagement [3]. Learning analytics were used in enhancing student experience and retention rates as well as driving interventions at student module and qualification levels.

In Australia at the University of New England, social media is the main platform that is used in engaging students and promoting learning analytics and this has fostered a sense of community among the students both those studying full time at the university and those studying part time [7]. Furthermore, learning analytics helped instructors to identify which students needed support and helped them in creating probabilities of retention scores. At Wollogong University in Australia, learning analytics were used using a system known as SNAPP and it has the ability of visualizing relationships that exist between participants in real time in the form of a network diagram. This enabled instructors to encourage engagements among students especially those students who were less connected with their peers [7].

It is crucial to know that adapting any new technology has challenges that come with it and this is also the same with the adoption of learning analytics in higher education. The following key points are challenges that have been recorded by research in the literature:

- The adoption of learning analytics in an educational sector implies creating a new culture among all stakeholders in order to adapt to the new processes in place and that calls for change management [8].

- Like every new technology, adopting learning analytics comes with additional costs that must be incurred and this normally affects budgets [9].

- Data plays an important role in the implementation of learning analytics systems as successful implementation relies on both effective data integration and the quality of the data and the main restriction often come in play when data systems are not interoperable [8].

- Lack of dedicated data management systems for the production of datasets within a short space of time [9].

An educator should be able to quickly get an insight of the entire learning process by using learning analytics through the use of effective virtualization techniques to monitor users' movements. Current learning management systems provide little insight as far as data analytics is concerned, mainly the number of users logged in and the time log is reflected. Little or no information is given on the movements of users' online. Given above limitations with most of the current systems, Researchers in [1] proposed a model to help in the adoption of learning analytics known as the Learning Analytics
Acceptance Model (LAAM). A learning analytics tool called LOCO-Analyst was used in the study to create the LAAM model and investigate the impact of the aforementioned factors. Learning analytics are provided at varying levels of interest using LOCO-Analyst. The model is centered upon the study by [10] who described perceived usefulness as the extent by which an individual believes that their task performance will be improved as a result of using the system. Furthermore, Ease of use is the extent by which an educator believes that a system will be free of effort.

According to a study done by [11] it was found out that learning analytics varies depending on one's interest whether they are interested in a university, department, specific course or a region. The researcher categorizes the interests into three distinct groups, micro, meso and macro analytics. Researchers in [12] described a model for learning analytics:

- What: This dimension seeks to know the type of information that has been collected, managed and used.

- Who: This seeks to find the actors involved who will ultimately receive results.

- Why: Which objectives will be used in order to analyze the collected data.

- How: Which methods will be used in analyzing available data analytics that are based on four dimensions?

The architecture developed by [2] shows how data from various learning environments is fed into the learning analytics warehouse. Predictive analytics takes place at the center of the architecture resulting in actions being coordinated by the system. Analytics can be visualized in a series of dashboards allowing both students and instructors to engage and compare their progress with others. Using such information allows both instructors and students to plan and set targets. Furthermore, the student consent service available allows students to share their information to certain people therefore maintaining privacy of data captured, Jisc's learning analytics software is available for free to institutions for the first two years and the system is cloud based allowing institutions to share the scalable structure yet maintaining their data and the system can be customized easily.

The Unified Technology of Acceptance and Use of Technology (UTAUT) forms the basis of this study. The study is based on all dimensions in the model. Technology Anxiety is another dimension that is not part of UTAUT that was adopted from a study by [6], [13] however the researchers call this computer anxiety in their study. The modified model used in this study has a total of seven dimensions. These dimensions will be used to find out the determinants of learning analytics adoption by students in North Cyprus.

\section{Methodology}

\section{A. The Aim and Hypotheses}

The study directly aims to evaluate the correlation between the Performance Expectancy and Technology Use in different dimensions as stated in the following stipulated hypothesis as depicted in Fig. 1. 
H1: Performance Expectancy (PE) will have a positive effect on learning analytics (LA) Usage Intention on the adoption of learning analytic tools in higher education.

H2: Effort Expectancy (EE) will have a positive effect on LA Usage Intention on the adoption of learning analytic tools in higher education.

H3: Social Influence (SI) will have a positive effect on LA Usage Intention on the adoption of learning analytic tools in higher education.

H4: LA usage intention will have a positive effect on LA Usage Behavior on the adoption of learning analytic tools in higher education.

H5: Facilitating Conditions (FC) will have a positive effect on LA Usage Behavior of learning analytics tool adoption.

H6: LA Anxiety will have a positive effect on LA Usage Behavior when it comes to learning analytics tool adoption.

\section{B. The Research Model}

The research model that will be used in this study comprises of the Unified Technology of Acceptance and Use of Technology (UTAUT) model by [14] which was modified and another dimension Technology anxiety was added. The model used in this study was adopted from a study by [6] and [13]. The model comprises of 7 dimensions namely performance expectancy, effort expectancy, social influence, technology use intention, technology use behavior, facilitating conditions and technology anxiety. The aim of the study is to explore these dimensions and find out to what extent does each dimension affects determinants of learning analytics tools used by students which the proposed model was depicted in Fig. 1.

\section{The Participants}

Participants who took part in this study were students were currently studying at three universities in North Cyprus. In the time of the study, the total population of 102944 students were studying in North Cyprus. Given that the margin of error is
$5 \%$, a normal distribution expected and $95 \%$ confidence interval it then means that the recommended sample size will be 383. This makes the sample size of 718 participants satisfactory for further analysis.

The participations were voluntary, meaning anyone was free to take part in the study. Furthermore the participant information was anonymously recorded, no personal information was collected that could be used to trace back the participant. Due to several departments at the universities with students specializing in various fields, in this study for the purpose of data analysis participants' department information was divided into two distinct categories namely STEM (Sciences, Technology, Engineering and Mathematics) specifically for students with a technical background and others for non-technical students.

The total number of questionnaires that were distributed were 800. A total of 718 questionnaires which were considered as valid and were further entered into SPSS for analysis. Descriptive statistics and bivariate correlations were used in analyzing the data.

\section{The Demographics of the Participants}

The majority of the students were in the age group 17-26 which totaled 334 (46.5\%), followed by age group 27-36 years which were 231 students which constituted $32.2 \%$ of the total participants and the last age group 37 years and above had 153 students $(21.3 \%)$ and this group was mainly dominated by $\mathrm{PhD}$ students and a few masters students.

In addition, among the three distinct levels of study, a lot of the participants were undergraduate students who comprised of 391 students $(54.5 \%)$ of the total participants. Masters students who took part in the study were 244 (34\%) and $\mathrm{PhD}$ students were 83 (11.5\%). The numbers narrow down as the levels go higher in any educational setting. The STEM department which comprised of students in technical fields and science subjects totaled $424(59.1 \%)$ whereas those from other departments were 294 (40.9\%).

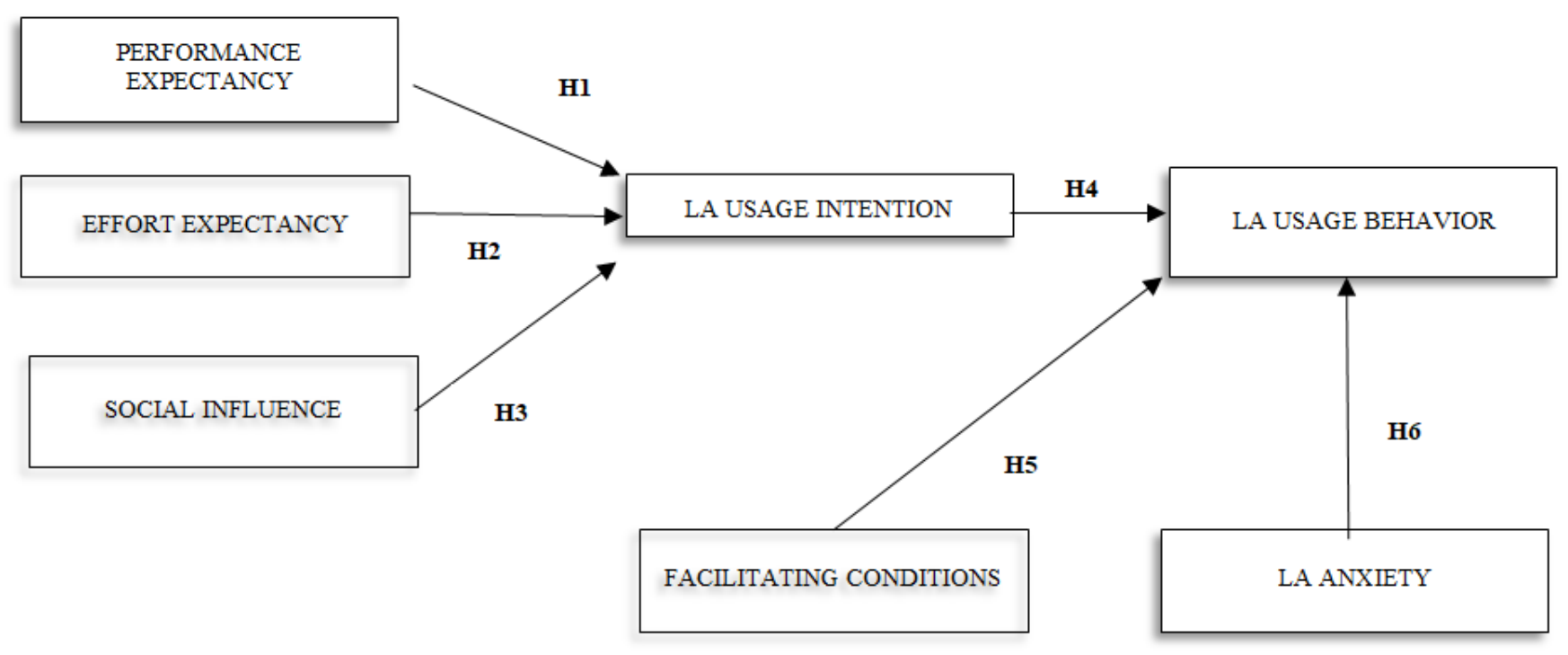

Fig. 1. The Research Model of the Study. 


\section{E. The Data Collection}

A paper based questionnaire was used to obtain information from participants. The questionnaire had a total of 28 questions with the first part asking general demographic data. The other seven dimensions, Performance Expectancy, Effort Expectancy, Social Influence, Learning Analytics Usage Intention, Learning Analytics Usage Behavior, Facilitating Conditions and Learning Analytics Anxiety were based on a 5 Likert scale. Apart from the 4 questions that were based on the demographic data of the participant. The learning analytics was described in detailed through examples. The
Table I represents the items corresponds to the aforementioned dimensions.

\section{F. Reliability}

The Cronbach's alpha internal consistency coefficient was used to check reliability in SPSS. Acceptable reliability should range from 0.6 coefficient going upwards, anything less than that is considered unacceptable and amendments must be done until a satisfactory result is obtained [15]. As shown in the Table II, all the dimensions had a reliability of more than 0.6 coefficient which meant all dimensions had satisfactory internal consistency.

TABLE I. THE ADOPTED QUESTIONNAIRE

\begin{tabular}{|c|c|}
\hline Secti & II: PERFORMANCE EXPECTANCY \\
\hline 1. & I think Learning analytics will increase my productivity. \\
\hline 2. & I think Learning analytics enables me to accomplish tasks quicker. \\
\hline 3. & I think Learning analytics allows me to access more information about my courses. \\
\hline Sect & III: EFFORT EXPECTANCY \\
\hline 4. & Using learning analytics will be easy and intuitive. \\
\hline 5. & I find learning analytics tools easy to use \\
\hline 6. & I believe it would be so easy for me to become skillful at using learning analytics tools. \\
\hline Secti & IV: SOCIAL INFLUENCE \\
\hline 7. & People who influence my behaviour think I should use learning analytics tools. \\
\hline 8. & My supervisors have been helpful in introducing learning analytics tools to me. \\
\hline 9. & People who are important to me think I should use learning analytics tools. \\
\hline 10. & I will use learning analytics even if no one I know is using it. \\
\hline Sect & V: LEARNING ANALYTICS USAGE INTENTION \\
\hline 11. & I predict my university will use learning analytics tools in the next months. \\
\hline 12. & My university intends to use a learning analytics tools in the near future. \\
\hline 13. & My university plan to use learning analytics tools in the distant future. \\
\hline 14. & I intend to use learning analytics tools in the future \\
\hline 15. & I predict I will use learning analytics tools in the next months. \\
\hline 16. & My university has recently started using learning analytics tool. \\
\hline 17. & My university has already been using learning analytics tool for a while. \\
\hline Sect & VI: LEARNING ANALYTICS USAGE BEHAVIOR \\
\hline 18. & I often access learning analytics tools using the internet. \\
\hline 19. & The university has been of help in enabling me to use learning analytics. \\
\hline 20. & I am willing to use learning analytics in my studies. \\
\hline 21. & Using learning analytics tools will lead to a better overall learning experience \\
\hline Sect & VI: FACILITATING CONDITIONS \\
\hline 22. & I have the resources necessary to use learning analytics. \\
\hline 23. & I have the knowledge necessary to use learning analytics. \\
\hline 24. & Learning analytics tools are compatible with other learning tools I use. \\
\hline Sect & VIII: LEARNING ANALYTICS ANXIETY \\
\hline 25. & I feel apprehensive about using learning analytics tools. \\
\hline & It scares me to think that I could lose a lot of information using learning analytics tool by hitting the wrong key. \\
\hline & I am hesitant to use learning analytics for fear of making mistakes which I cannot correct. \\
\hline & Learning analytics tools are somehow intimidating to me. \\
\hline
\end{tabular}


TABLE II. QUESTIONNAIRE CONSTRUCTS AND RELIABILITY TESTS

\begin{tabular}{|l|l|l|}
\hline Constructs: & Number of Items & Cronbach's Alpha \\
\hline Performance Expectancy(PE) & 3 & .688 \\
\hline Effort Expectancy(EE) & 3 & .675 \\
\hline Social Influence(SI) & 4 & .684 \\
\hline LA Usage Intention(LAUI) & 7 & .774 \\
\hline LA Usage Behaviour(LAUB) & 4 & .706 \\
\hline Facilitating Conditions(FC) & 3 & .794 \\
\hline LA Anxiety(LAA) & 4 & .756 \\
\hline TOTAL & 28 & .851 \\
\hline
\end{tabular}

\section{RESULTS AND DISCUSSION}

\section{A. The Relationship between Performance Expectancy (PE) and Learning Analytics usage Intention}

A Pearson Correlation was computed in order to understand the nature of the relationship existing between the independent and dependent variables. There was a weak negative correlation between Performance Expectancy and Learning Analytics Usage Intention as shown by the following values; $\mathrm{r}=-.075, \mathrm{n}=718$ and $\mathrm{p}=.044$. Since $\mathrm{p}<=0.05$, it was concluded that there is a relationship between the two aforementioned variables. This means that if students are aware of how learning analytics operates and if it satisfies their requirements, they will be ready to adopt learning analytics into their education.

\section{B. The Relationship between Effort Expectancy (EE) and Learning Analytics usage Intention}

A Pearson Correlation was computed in order to understand the nature of the relationship existing between the independent and dependent variables. There was a weak negative correlation between Effort Expectancy and Technology Use Intention as shown by the following values; $r$ $=-.197, \mathrm{n}=718$ and $\mathrm{p}=.000$. Since $\mathrm{p}<=0.05$, There exists a relationship between the two aforementioned variables. This implies that when students perceive that little or no effort is needed for one to master learning analytics, they are keen on adopting the technology.

\section{The Relationship between Social Influence (SI) and Learning Analytics usage Intention}

A Pearson Correlation was computed in order to understand the nature of the relationship existing between the independent and dependent variables. There was a weak positive correlation between Social Influence and Learning Analytics Usage Intention as shown by the following values; $\mathrm{r}=.045, \mathrm{n}=718$ and $\mathrm{p}=.224$. Since $\mathrm{p}>0.05$. It was concluded that there is no relationship between the two aforementioned variables. This means that friends and family have no influence on one owns decision when it comes to using learning analytics, it is independent decision. This means that even if peers are using learning analytics tools in their studies one may still decide not to use, close associates have no influence. Close associates such as friends and family have a positive influence in the technology that one uses. If fellow friends and family members are already using learning analytics for their studies they are most likely to influence non-users who will eventually adopt to the new technology. Further investigations may be required to understand variations in results.

\section{The Relationship between Learning Analytics usage Intention and Learning Analytics usage behavior}

A Pearson Correlation was computed in order to understand the nature of the relationship existing between the independent and dependent variables. There was a weak negative correlation between Learning Analytics Usage Intention and Learning Analytics Usage Behavior as shown by the following values; $\mathrm{r}=-.179, \mathrm{n}=718$ and $\mathrm{p}=.000$. Since $\mathrm{p}<=$ 0.05 , we accept the hypothesis and conclude that there is a relationship between the two aforementioned variables. This mean that one's behavior towards using learning analytics is strongly determined by his or her intention to use the technology now or in future. When students intend to use learning analytics they show a positive behavior towards the technology whereas when one does not intend to use the technology they tend to show negative attitude.

What students exhibit is a clear sign of whether they intend to use learning analytics now or in future. A negative behavior is often associated with students who are not keen on adopting the technology.

\section{E. The Relationship between Facilitating Conditions $(F C)$ and Learning Analytics usage behavior}

A Pearson Correlation was computed in order to understand the nature of the relationship existing between the independent and dependent variables. There was a strong positive correlation between Facilitating Conditions and Technology Use Behavior as shown by the following values; $r$ $=.734, \mathrm{n}=718$ and $\mathrm{p}=.000$. Since $\mathrm{p}<=0.05$. It was concluded that there is a relationship between the two aforementioned variables. This means that the way a student behaves towards using learning analytics is strongly influenced by other factors that contribute towards accepting the technology such as if they have the resources needed, do they have the knowledge required and will the technology be compatible with other learning tools they are currently using. All these are facilitating conditions that affect user behavior. This means that several factors should be considered prior to adoption and if all factors considered by the student are considered ideal then their behavior towards the usage of learning analytics change. The facilitating conditions can be changed to suit students need and that will result on a positive effect on behavior, for example if one of the factors that students 
consider as important is compatibility, it is important for educational institutions to make sure that learning analytic tools introduces can easily be integrated into current learning tools. The use of learning analytics can improve student retention which has an impact on the intention to use as suggested by [16]. Additionally, researcher in [16] reported that learning analytics usage provides aid to remedial students suggesting additional learning resources and customize learning progress and enhancing student achievement.

\section{F. The Relationship between Learning Analytics Anxiety and Learning Analytics usage behavior}

A Pearson Correlation was computed in order to understand the nature of the relationship existing between the independent and dependent variables. There was a moderate positive correlation between Technology Anxiety and Technology Use Behavior as shown by the following values; $r$ $=.503, \mathrm{n}=718$ and $\mathrm{p}=.000$. Since $\mathrm{p}<=0.05$, It was concluded that there is a relationship between the two aforementioned variables. If students are afraid of using technology they tend to portray a negative behavior towards the technology and if they are curious to try the technology then they are likely to portray a positive behavior.

Technical anxiety, learning analytics anxiety in particular is defined as a feeling of uneasiness when it comes to the use of new technology hence learning analytics. The technology anxiety affects user behavior when it comes to adoption of new technology. The researchers encouraged educational institutions to first make students comfortable with using technology prior to adoption that way successful adoption will be achieved.

Fig. 2 illustrates the research model of the study, the $r$ values between each independent and dependent variables. In addition, Table III represents the results of the study with correlation coefficients as described earlier. It is clearly seen that five of the hypothesis were supported and the dashed lines showed that there was no significant correlation between the two variables.

To sum up, there was a weak negative correlation between Performance Expectancy and Learning analytics usage Intention implying an inverse relationship between the two variables as one variable increased, the other variable decreased. This hypothesis was supported meaning there is a relationship between PE and LAUI. When students are aware of how a technology operates and if it satisfies their requirements they will be ready to adopt learning analytics into their education. There was also a negative weak correlation between Effort Expectancy and Learning Analytics Usage Intention implying an inverse relationship between the two variables as one variable increased, the other variable decreased. This hypothesis was also supported meaning there is a relationship between EE and LAUI. When students perceive that little or no effort is needed for one to master learning analytics they are keen on adopting the technology.

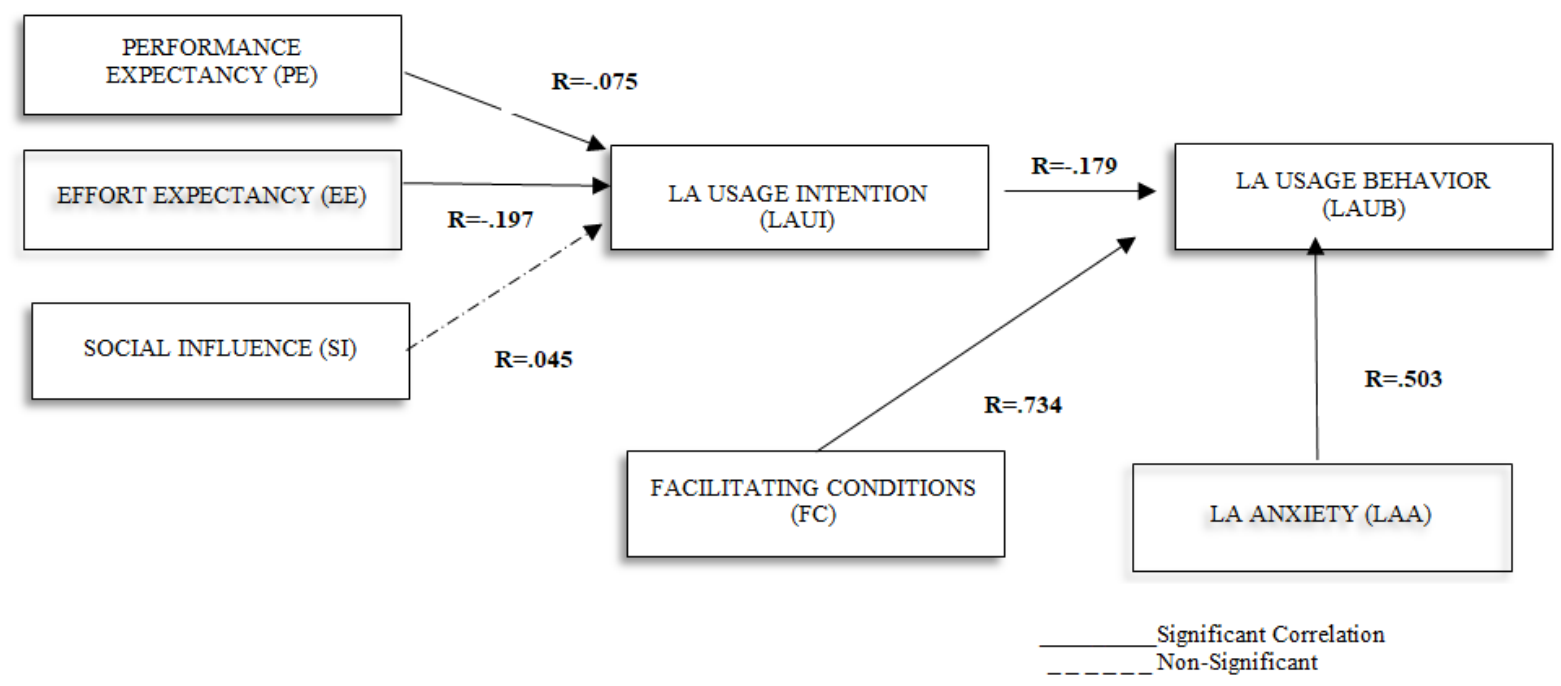

Fig. 2. Summary of Findings and Correlations.

TABLE III. SUMMARY OF FINDINGS

\begin{tabular}{|l|l|l|l|l|l|}
\hline Hypothesis & IV & DV & Supported & Correlation coefficient (+/-Positive/Negative) & R value \\
\hline H1 & PE & LAUI & Yes & Weak - & -.075 \\
\hline H2 & EE & LAUI & Yes & Weak - & -.197 \\
\hline H3 & SI & LAUI & No & Moderate + & .045 \\
\hline H4 & LAUI & LAUB & Yes & Weak - & -.179 \\
\hline H5 & FC & LAUB & Yes & Strong + & .734 \\
\hline H6 & LAA & LAUB & Yes & Moderate + & .503 \\
\hline
\end{tabular}


There was also a positive weak correlation between Social Influence and Learning analytics usage Intention implying that as one variable increase, the other variable decrease. This hypothesis was rejected meaning there is no relationship between SI and LAUI when it comes to learning analytics. This means that friends and family have no say as to influence ones decision when it comes to using learning analytics, it is ones independent decision. This mean that even if peers are using learning analytics tools in their studies one may still decide not to use, close associates have no influence.

There was a negative weak correlation between Learning Analytics Usage Intention (LAUI) and Learning Analytics Usage Behavior (LAUB) implying an inverse relationship between the two variables as one variable increased, the other variable decreased. This hypothesis was also supported meaning there is a relationship between LAUI and LAUB. This mean that one's behavior towards using learning analytics is strongly determined by his or her intention to use the technology now or in future. When students intend to use learning analytics they show a positive behavior towards the technology whereas when one does not intend to use the technology they tend to show negative attitude.

There was a strong positive correlation between Facilitating Conditions and Learning Analytics Usage Behavior meaning as one variable increase, the other variable also increase. This hypothesis was supported meaning there is a strong relationship between FC and LAUB. This means that the way a student behaves towards using learning analytics is strongly influenced by other factors that contribute towards accepting the technology such as if they have the resources needed, do they have the knowledge required and will the technology be compatible with other learning tools they are currently using. All these are facilitating conditions that affect user behavior.

There was a moderate positive correlation between Learning Analytics Anxiety (LAA) and Learning Analytics Usage Behavior. This means that as one variable increase, the other variable also increase. This hypothesis was supported meaning there is a relationship between LAA and LAUB. If students are afraid of using technology they tend to portray a negative behavior towards the technology and if they are curious to try the technology then they are likely to portray a positive behavior.

In a systematics review study carried out with 43 papers in the related literature by researchers in [17], 12 studies were related to benefits of using Learning analytics and how users perceptions about using LA tools among other aspects as; student retention, assessment, customized learning experiences, usefulness of LA tools, satisfaction, interactions, development, self-reflection, engagement, design of learning and scenarios. Researchers in [18] remarked that students anticipate learning analytics tool that they intend to use or already using should backup and organize their learning progress, should give insights about the progress, should communicate and adjust their needs instantly, and display the outcomes of all learning activities. Researchers in [19] addressed that The Technology Acceptance Model (TAM) proposed by [10] and the Universal Technology Adoption and
Use Theory (UTAUT) proposed by [14] which investigates the human factors related to adoption of specific technologies, including perceptions, beliefs, attitudes are particularly relevant for learning analytics adoption theories. Some studies yield to contradictory findings that although learning analytics tools adoption promise improvement in learning, the actual contribution to the educational practice has minor impact but it has been improving towards gaining deeper insights regarding students' learning processes [20].

\section{CONCLUSION}

In conclusion, students apparently are keen on adopting learning analytics. This is so because five of six hypothesis used were significantly supported by the results. Students indicated that they have study applications from Play Store they use with a customized dashboard and reminders on their phones also inform them that it is now time to study and to switch subjects. This is evidence that the mobile devices already in use can be used even more effectively for learning analytics. It is also crucial for institutions to embark on workshops to educate both students and instructors on the benefits of adopting to this technology. Students' learning analytics use should be endorsed by the institutions and training programs on using learning analytics tool should be provided to students, instructors and academic advisors.

\section{SUGGESTIONS}

- The study only focused at a small population of students at three universities only. We strongly recommend a larger population group to be considered in future to really give a better view of the technology and its acceptance levels.

- The study only focused at understanding the determinants of adopting learning analytical tools in education with a strong focus on student perspective. Future research is strongly recommended that will focus on instructors to fully understand both perspectives.

- Institutions should come up with policies that encourage adoption of such technologies and implement workshops so that it will yield in successful adoption as all key stakeholders will be aware of what is required of them.

- Computer basics are the foundation of understanding how learning analytical tools work. It is therefore crucial for institutions to make such studies compulsory among all disciplines whether technical or non-technical.

Instructors as decision makers should be equipped with emergent skills in collecting, interpreting and analyzing student progress and learning and proposing remedial solutions [21]. New data mining competences will be inevitable in future not only for instructors but also for students. Along the same lines, more user-friendly tools will have to be introduced and tested by e-learning faculty. The integration of learning analytics with social media tools will enable instructors to make more effective, efficient timely decisions on the learning progress of students [22]. 


\section{REFERENCES}

[1] L. Ali, M. Asadi, D. Gašević, J. Jovanović, and M. Hatala, "Factors influencing beliefs for adoption of a learning analytics tool: An empirical study," Computers \& Education, vol. 62, pp. 130-148, 2013.

[2] N. Sclater, A. Peasgood, and J. Mullan, "Learning Analytics in Higher Education: A review of UK and international practice full report", Learning Analytics in Higher Education, 4(2), 1-32, 2017.

[3] G. Bonnin, A. Boyer, Higher Education and the Revolution of Learning Analytics, ICDE Insight Paper, Sydney, Australia: International Council for Distance Education, pp. 1-20, 2016.

[4] N. Khan, I. Yaqoob, I. A. T. Hashem, Z. Inayat, W. K. Mahmoud Ali, M. Alam, M. Shiraz, and A. Gani, "Big Data: Survey, Technologies, Opportunities, and Challenges," The Scientific World Journal, vol. 2014, pp. 1-18, 2014.

[5] O. Adejo, and T. Connolly, "Learning Analytics in Higher Education Development: A Roadmap". Journal of Education and Practice, vol. 8 no. 15, pp.156-163, 2017.

[6] N. Nistor, B. Baltes, M. Dascălu, D. Mihăilă, G. Smeaton, and Ş. Trăuşan-Matu, "Participation in virtual academic communities of practice under the influence of technology acceptance and community factors. A learning analytics application," Computers in Human Behavior, vol. 34, pp. 339-344, 2014.

[7] N. Friesen, "Learning Analytics: Readiness and Rewards" Canadian journal of learning and technology, vol. 39, no. 4, pp.45-48, 2013.

[8] B. Daniel, "Big Data and analytics in higher education: Opportunities and challenges," British Journal of Educational Technology, vol. 46, no. 5, pp. 904-920, 2014.

[9] A. J. J., Jordaan, and A. Van der Merwe, "Best practices for learning analytics initiatives in higher education" In W. R. Kilfoil (Ed.), Moving beyond the hype: A contextualised view of learning with technology in higher education, pp. 53-58, Pretoria: Universities South Africa, 2015.

[10] F. D. Davis, "Perceived Usefulness, Perceived Ease of Use, and User Acceptance of Information Technology," MIS Quarterly, vol. 13, no. 3, p. 319, 1989.

[11] K. Buckingham, "Adoption of learning analytics in India” International Journal of Scientific Engineering and Applied Science, vol. 2, no. 2, pp. 432-438, 2016.
[12] M.A. Chatti, V. Lukarov, H. Thüs, A. Muslim, A.M.F Yousef, U. Wahid, , C. Greven, A. Chakrabarti. and U. Schroeder, "Learning aanalytics: Challenges and future research directions". eleed, vol. 10, no.1, 2014.

[13] N. Nistor, T. Lerche, A. Weinberger, C. Ceobanu, and O. Heymann, "Towards the integration of culture into the Unified Theory of Acceptance and Use of Technology," British Journal of Educational Technology, vol. 45, no. 1, pp. 36-55, 2012.

[14] Venkatesh, Morris, Davis, and Davis, "User Acceptance of Information Technology: Toward a Unified View," MIS Quarterly, vol. 27, no. 3, p. 425-478, 2003.

[15] G. Sekaran, "Understanding reliability analysis".,International Journal of Educational Technology in Higher Education, vol. 17 no.1, pp. 2028,2000 .

[16] B. T. M. Wong, "Learning analytics in higher education: an analysis of case studies," Asian Association of Open Universities Journal, vol. 12, no. 1, pp. 21-40, 2017.

[17] K. Mangaroska and M. Giannakos, "Learning Analytics for Learning Design: A Systematic Literature Review of Analytics-Driven Design to Enhance Learning," IEEE Transactions on Learning Technologies, vol. 12, no. 4, pp. 516-534, 2019.

[18] C. Schumacher and D. Ifenthaler, "Features students really expect from learning analytics," Computers in Human Behavior, vol. 78, pp. 397 407, 2018.

[19] J. Lester, C. Klein, H. Rangwala, \& A. Johri, "Learning Analytics in Higher Education: ASHE Higher Education Report", John Wiley \& Sons, 2017.

[20] O. Viberg, M. Hatakka, O. Bälter, and A. Mavroudi, "The current landscape of learning analytics in higher education," Computers in Human Behavior, vol. 89, pp. 98-110, 2018.

[21] B.C. Czerkawski, "When Learning Analytics Meets E-Learning". Online Journal of Distance Learning Administration, vol. 18, no.2, 15,2015 .

[22] S. Basaran, "Faculty's Social Media usage in Higher Education Embrace Change or Left Behind," International Journal of Advanced Computer Science and Applications, vol. 10, no. 10, 2019. 